\title{
Bağlanma Örüntüleri ve Evlilik Uyumu Arasındaki İlişkide Eşe Yönelik Kişilerarası Şemaların Aracı Yolu
}

\author{
The Relationship Between Attachment Styles, Interpersonal Schemas for \\ Partner and Marital Adaptation
}

\section{Fatma Mahperi HEKİMOĞLU * Sait ULUÇ **}

Öz: Bu çalışma kapsamında evlilik uyumu ile bağlanma örüntüleri arasındaki ilişkide kişilerarası şemaların aracı rolünün bootstrap analizi ile incelenmesi amaçlanmaktadır. Araştırmanın örneklemi 135 kadın ve 133 erkek olmak üzere, 268 evli çiftten oluşmaktadır. Yakın İlişsilerde Yaşantılar Envanteri-II (YIYE-II), Kişilerarası Şemalar Ölçeği (KŞÖ) ve Çiftler Uyumu Ölçeği (ÇUÖ) ölçüm araçları olarak kullanılmıştır. Araştırma sonuçlarına göre güvensiz bağlanma örüntüsüne sahip evli bireylerin evlilik uyumları güvenli bağlananlara kıyasla daha düşüktür. Güvensiz bağlanma örüntüleri arasında ise kaçınıcı bağlananların evlilik uyumları kaygılı bağlananlara göre daha düşüktür. Güvensiz bağlanma ve evlilik uyumu arasındaki ilişkide ise yakınlık ekseninin (dostluk ve düşmanlık kișilerarası şemaları) aracı rolü bulunurken, kontrol ekseninin (baskınlık ve pasiflik kişilerarası şemalarının) aracı etkisi bulunmamıştır. Çalışma bulguları kişilerarası şemalar, bağlanma örüntüleri ve evlilik uyumu arasındaki ilişkinin mekanizmasının anlaşılması açısından önemli bulgular sunmaktadır. Araştırma bulguları ilgili alan yazın doğrultusunda ele alınmıştır.

Anahtar sözcükler: Kişilerarası Şemalar, Evlilik Uyumu, Bağlanma Örüntüleri, İlişki Kalitesi

Abstract: The aim of this study into the role of interpersonal schemas in the relationship between marital adjustment and attachment patterns was investigated through bootstrap analysis. In this study the sample consisted of 268 married couples, 133 were men and 135 were women. All the individuals who participated in this study completed the Dyadic Adjustment Scale (DAS), the Interpersonal Schema Questionnaire (ISQ) and the Experiences in Close Relationship II (YIYE-II). According to the results, married individuals with insecure attachment patterns had lower marital adjustment than those with secure attachment. Among the insecure attachment patterns, it was found that avoidant couples had a lower marital adjustment than anxious ones. In the relationship between insecure attachment and marital adjustment, the proximity axis (friendship and hostility interpersonal schemes) was found to have a significant mediator role. On the other hand, the control axis (dominance and passivity interpersonal schemes) was found not to have a mediator role. These findings highlighted the importance of interpersonal schemas as an underlying mechanism, through the relationship between attachment patterns and marital adaptation in marriage. The findings from this research are discussed within the contect of the related literature.

Keywords: Interpersonal Schema, Marital Adjustment, Attachment Style, Quality of Relationship

\footnotetext{
* Dr. Arş. Gör., Akdeniz Üniversitesi, Edebiyat Fakültesi, Psikoloji Bölümü, Antalya. mahperiuluyol@akdeniz.edu.tr ckumru@pau.edu.tr, https://orcid.org/0000-0002-7879-9807

** Doç. Dr., Hacettepe Üniversitesi, Edebiyat Fakültesi, Psikoloji Bölümü, Ankara. psysait@hacettepe.edu.tr, https://orcid.org/ 0000-0002-7048-8545
} 
Evlilik belki de en fazla kültürel çeşitliliğe sahip olgulardan biridir. Her kültür, evliliği kendi hukuksal ve geleneksel kodları çerçevesinde tanımlamakta, düzenlemekte ve sınırlamaktadır. $\mathrm{Bu}$ çeşitlilik zaman zaman kültürlerarası düzeyde önemli çatışmalara yol açsa da evliliğin kalitesinin hem bireyin kendisi hem de aile sisteminin tamamı üzerinde önemli etkileri olduğu genel olarak kabul görmektedir (Minuchin 1974). Evliliğin kalitesindeki bozulmaların bireylerin iyilik halini bozup, psikolojik ve fizyolojik işlevsizlik düzeyini arttırdığı tartışılmaktadır. Örneğin, yakın ve uyumlu romantik ilişkilerin koroner kalp rahatsızlığı gibi sağlık risklerini azalttığına (Smith \& Baucom 2017) buna karşın yoğun çatışma yaşayan çiftlerin yüksek tansiyon riski taşıdıklarına dair çalışma bulguları bulunmaktadır (Troxel et al. 2017). Ayrıca, ilişki kalitesi sadece fizyolojik olarak değil psikolojik olarak da kişileri etkileyebilmektedir (örn. Whisman et al. 2004; Carr et al. 2014).

Alan yazın incelendiğinde evlilik kalitesinin göstergesi olarak evlilik doyumu, evlilik uyumu, evlilik bütünlüğü gibi farklı kavramların kullanıldığı görülmektedir (Spanier 1976). Evliliğin niteliğini değerlendiren çalışmalarda özellikle çiftler arasındaki uyumun önemli bir rol oynadığı belirtilmektedir (Erbek et al. 2005). Bu bağlamda evlilik ilişkisinin kalitesini tanımlamak için yaygın olarak kullanılan evlilik uyumu kavramının içeriğine dair farklı açıklamalar yapılmıştır. Örneğin, Boden et al. (2010) eşlerin ilişkilerinde önemli konular hakkında genellikle çatışma yaşamadığı, ortak bir fikirde bulaşabildikleri, bir konu hakkında çatışma yaşandığında ise çözüme ulaştıracak işlevsel stratejilerin kullanılabildiği ilişsilerin evlilik uyumunun yüksek olduğunu belirtmiştir. Benzer şekilde Sabatelliu de (1988) evlilik uyumunu; eşlerin karş1lıklı iletişim kurabildiği, ortaya çıkan fikir ayrılıklarının, çatışmaların iki tarafın da memnun olacağ şekilde çözüme ulaştırılabildiği, genel olarak çiftlerin ilişkilerinden doyum aldığ ilişkiler olarak tanımlamaktadır. Bu nedenle, evlilik uyumunu bozan faktörlerin belirlenmesi, çiftler arasındaki çatışmaların azaltılmasında ve ilişki kalitesinin arttırılmasında önemli rol oynayabilmektedir.

Evlilik uyumunu eşlerin yakın duygusal ilişkilerdeki bağlanma eğilimleri ve kişilerarası ilişkilerdeki tamamlanma beklentilerinden ayrı düşünmek pek mümkün değildir. Özellikle, eşlerin bağlanma örüntülerinin evlilik uyumu üzerinde etkili olduğuna işaret eden çok sayıda çalışma bulunmaktadır (MacLean 2001; Collins \& Feeney 2004; Erdoğan-Taycan \& ÇepikKuruoğlu 2013; Gündoğan 2015). Bowlby'e (1969) göre bağlanma deneyimleri zaman içinde kendilik, diğeri ve yakın duygusal ilişkinin niteliğini ifade eden bilişsel yapılara (çalışan modellere) dönüşmektedir. Böylece erken dönem yaşam deneyimleri kişilerarası beklentileri de içeren şemalar aracılığıyla yetișkin yaşamına aktarılmakta ve sürekliliğini korumaktadır. Hazan ve Shaver (1987) çocukluk dönemindeki bağlanma örüntüleri ile yetişkinlerin romantik ilişkideki eşle bağlanma örüntülerinin önemli benzerlikler gösterdiğine ve buna bağlı olarak kişilerin ilişki deneyimlerinin farklılaşabildiğine vurgu yapmaktadır. Güvenli bağlanma örüntüsüne sahip kişilerin eşlerinin destekleyici ve güvenilir olduğu inancına sahip oldukları, ilişkide oluşan tartışmalar sırasında da bu inançlarını sürdürdükleri için karşılıklı yakın ve doyurucu bir ilişki içerisinde oldukları ileri sürülmektedir (Mikulincer \& Shaver 2007). Ek olarak, güvenli bağlanan bireylerin belirsizliği ve kaygı yaratan durumları yapıcı bir şekilde ele alırken, kaygılı bağlananların kendi endişelerine odaklanıp, eşlerinden olası gelebilecek dışlama veya reddedilme sinyallerine karşı tetikte bekledikleri düşünülmektedir. İlişki içerisinde güvenli bağlananların duygu ve düşüncelerini daha iyi ve net ifade ederken, güvensiz bağlananların eşlerinden gelen sinyallere karşı daha az duyarlı oldukları ve duygularını karşı tarafa yansıtma konusunda güçlük yaşadıkları belirtilmektedir (Feeney 2004). Kaçınıcı bağlananların ise evliliklerinde daha çok uyumsuzluk yaşadıkları (Pollard et al. 2014) ve ilişki kalitelerini daha olumsuz olarak değerlendirdikleri belirtilmektedir (Noftle \& Shaver 2006). Bu nedenle, güvensiz bağlanma örüntüsüne sahip kişilerin evlilik uyumlarının daha düşük olacağı ileri sürülmektedir (örn. Özen 2012; Pollard et al. 2014; Young et al. 2017). 
Evlilik uyumunu etkileyebileceği düşünülen bir diğer faktör de kişilerarası şemalardır. Kişilerarası şemalar iki kişi arasında, bilinçli veya örtük bir şekilde tekrarlayan ilişki örüntüleridir (Kiesler 1983). İlişkilerdeki karş1lıklı tamamlanma ilkesini ilk öne süren Sullivan'dır (1953). Modele göre kişilerarası ilişkiler, yakınlık boyutu (dostluk ve düşmanlık kutupları) ile kontrol boyutu (baskınlık ve pasiflik kutupları) olmak üzere birbirini kesen iki eksen üzerinde yer almaktadır. Kişilerarası ilişkilerin de karşılıklılık ve tamamlanma prensipleri doğrultusunda şekillendiği ileri sürülmektedir (Kiesler 1983). Bu tartışmalara ek olarak kişilerarası şemaların, ilişki içerisinde karşı tarafın belirli davranışları sergilemesi için biçimlendiren veya bu yönde davranmaya zorlayacak şekilde organize olduğu düşünülmektedir. Örneğin iki kişi arasındaki ilişkide bir tarafın baskın davranışlar sergilemesinin, diğer tarafı pasif davranışlar sergilemeye yönlendirdiği düşünülmektedir. Eğer ilişki içerisinde baskın davranışlar karşısında karşı taraf tamamlayıcı tepki olan itaatkâr, uyumlu davranışları gösterirse ilişki içerisinde çatışma yaşanmamaktadır. Tam tersi baskın davranışlar karşısında, karşı taraf da baskın bir davranış örüntüsü sergilerse kişilerarası davranış örüntüsü tamamlanamamaktadır. İlişki içindeki tamamlayıcı tepki alınamadığında ise kişilerin bu durumu kendileri için bir tehdit olarak algıladıkları ve bunun sonucu olarak da kaygılarının yükseldiği belirtilmektedir. Ek olarak, modele göre yatay (yakınlık) eksenin tamamlayıcısı kendisidir. Buna göre yakınlaşmaya yönelik davranışlar, aynı eksen üzerinden tamamlanmakta ve dostça tepkiler, dostça tepkiler üretmektedir. Benzer şekilde düşmanca davranışlar aynı eksen üzerinden yine tamamlayıcısı olarak düşmanca tepkiler üretmektedir (Kiesler 1983; Safran \& Segal 1990; Baldwin 1992).

Safran ve Segal (1990), Kiesler'in (1983) kişilerarası kutuplu döngüdeki karşılıklılık ve tamamlanma ilkelerini temel alarak, kişilerarası şemalar yaklaşımını ileri sürmüştür. Kişilerarası Şema Kuramına (Safran \& Segal 1990; Baldwin 1992) göre her yeni etkileşimde şemalara uygun tekrarlayan davranış beklentisi içerisinde olunmaktadır. Kurama göre kişiler şemaları ile örtüşen uyaranları uymayanlara göre daha çabuk fark edip tepki vermekte ve böylece şemayı sürdürücü davranışlarda daha çok bulunulduğu düşünülmektedir (Markus 1977). Özellikle bu yaklaşım döngünün sadece bireysel düzeyde olmadığını, ilişki düzeyinde etkisinin olduğunu, dolayısıyla ilişkide döngüselliğin olduğu görüşünü savunmaktadır (Safran \& Segal 1990). Dahası kişilerin kendilerini ve diğerlerini nasıl algıladığı ve diğerlerine ilişkin beklentilerinin, kişilerarası davranışların belirlenmesinde kullanılan stratejiler üzerinde etkili olduğu düşünülmektedir.

Bowlby'nin (1969) öne sürdüğü içsel çalışan modeller kişilerarası şemaların çekirdeğini oluşturmaktadır. Kişilerarası ilişkiler perspektifinden bakıldığında zihinsel temsillere bağlı inanç ve beklentilerin, kişilerarası ilişkilerdeki davranışları ve beklentileri etkilediği savunulmaktadır (Gallo \& Smith 2001; Mikulincer \& Shaver 2007). Örneğin, güvenli bağlananlar, kendilerini sevilebilir ve diğerlerini güvenilir olarak algıladıkları için ihtiyaç anında diğerlerinden dostça tepki ve yardım geleceğine inanmaktadırlar. Güvensiz bağlananlar ise düşmanca davranışa karşı1ık düşmanca tepki alacaklarını, ihtiyaç anında yardım alamayacaklarını ve baskın davranmak istediklerinde de kendilerine izin verilmeyeceğine inanmaktadırlar (Bartholomew \& Horowitz 1991; Baldwin 1992). Bu nedenle, bağlanma örüntülerine göre ilişkilerde farklı kişilerarası problemlerin oluşabileceği düşünülmektedir (Horowitz et al. 1993; Uluç 2005; Tüzün 2006).

Evlilik ilişkisi düşünüldüğünde de çiftlerin birbirleriyle etkileşim içerisinde olması kaçınılmazdır. Alan yazında, eşler arasındaki kişilerarası döngünün evlilik uyumunu etkilediğini gösteren bulgular bulunmaktadır (Bodenmann \& Randall 2012; Donato et al. 2015). Türkiye'deki çalışmalarda ise evlilik uyumunu yordamada bağlanma boyutunun ele alındığ çalışmalarda çiftlerin bazı kişilik özellikleri (Dumlupınar-Aslan 2016; Sağlam 2016), savunma mekanizmaları (Elmas 2017) ve bazı sosyo-demografik değişkenlerin (Yalçın 2014) ilişkisi incelen- 
miştir. Bağlanma örüntülerinden kişilerarası şemalara ve kişilerarası şemalardan da evlilik uyumuna giden akış kuramsal düzeyde açık gibi görünmesine rağmen bu üç değişkeni bir süreç analizi çerçevesinde ele alan görgül bir çalışmaya rastlanmamıştır. $\mathrm{Bu}$ araştırma kapsamında kişilerarası şemalardaki, özellikle de yakınlık boyutundaki, tamamlanma beklentilerinin bağlanma örüntüleri ve evlilik doyumu arasında aracı bir rol üstleniyor olabileceği varsayımının test edilmesi hedeflenmiştir.

\section{Yöntem}

\section{Katılımellar}

Araştırma kapsamında 142 kadın ve 140 erkek olmak üzere toplam 282 evli yetişkine ulaşılmıştır. Analiz öncesi veri taramasında \%5'den fazla kayıp değeri olan, sistematik doldurma yapan ve uç değer olan verilerin temizlenmesinden sonra çalışmaya 135'i kadın ve 133'ü erkek olmak üzere 268 katılımcı ile devam edilmiştir. Kadınların yaş aralığ 121 ile 60 (Ort=35.12, $S S=8.09)$ arasında erkeklerin yaşları ise 22 ile 66 arasında $(O r t=40.64, S S=9.82)$ değişmektedir. Kadınlar için ortalama evlilik yaşının 25.35 (SS= 3.83), erkekler için ise 27.39 (SS= 4.76) olduğu tespit edilmiştir. Bu örneklem için katılımcıların ortalama evlilik süresinin 12 ile 648 ay arasında değiştiği $(O r t=132.03, S S=121.98)$ belirlenmiştir. Katılımcıların \% 33.6's1 çocuğu olmadığını, \% 29.1'i tek, \% 33.2'si iki ve \% 4.1'i üç veya daha fazla çocuğa sahip olduklarını bildirmiştir. Katılımcıların aylık geliri sosyo-ekonomik düzey (SED) göstergesi olarak kabul edilmiştir. Buna göre, katılımc1ların \% 17.2'si 1000-2000 TL, \% 22.1'si 2000-3000, \% 12.6's1 3000-4000; \% 47'si, 4000 TL- ve üstü toplam gelirlerinin olduğunu belirtmişlerdir. Psikiyatrik rahatsızlığı olanlar, birden fazla evlilik yapanlar ve bir yıldan daha az süredir evli olanlar çalışmanın dışlama kriterleri kapsamında veri setine dahil edilmemiştir.

\section{Veri toplama Araçları}

Demografik Bilgi Formu: Çalışma kapsamında araştırma değişkenleri ile ilişkili olduğu düşünülen sosyo-demografik özelliklerin belirlenmesi için ilgili alan yazın taranmış ve evlilik uyumu üzerinde rol oynayabileceği düşünülen yaş, evlilik şekli, evlilik süresi, ortalama gelir düzeyi, çocuk sayısı, eğitim seviyesi, yaşanılan yer, evlilik kararı-şekli gibi bazı demografik bilgilerden oluşan bir form oluşturulmuştur.

Yakın İlişsilerde Yaşantılar Envanteri-II (YIYYE-II): Ölçek, bireylerin romantik ilişkilerinde bağlanma boyutlarını değerlendirmek için Brennan, Clark ve Shaver (1998) tarafindan geliştirilmiştir. Sonrasında Fraley, Waller ve Brennan (2000), orijinal ölçeği temel alarak ölçüm duyarlılı̆̆ daha yüksek olan YIYYE-II'yi geliştirmişlerdir. Ölçek 7'li Likert tipinde 36 maddeden oluşmaktadır. Ölçeğin ilk 18 maddesi kaygı, kalan 18 maddesi ise kaçınma boyutunu değerlendirmektedir. Ölçeğin, Türk kültürü için psikometrik özellikleri, Selçuk et al. (2005) tarafından incelenmiştir. Ölçeğin iç tutarlık değeri, kaçınma alt boyutu için .90; kaygı alt boyutu için .86 olarak belirtilmiştir Ayrıca ölçeğin, test-tekrar test güvenirliği; kaçınma boyutu için .81, kayg1 boyutu için .82 olarak bulunmuştur. Bu çalışma kapsamında kaçınma için iç tutarlık katsayısı kayg1 için .81; kaçınma için .85 olarak bulunmuştur.

Çiftler Uyumu Ölçeği (ÇUÖ): Ölçek, Spanier (1976) tarafından evli veya birlikte yaşayan çiftlerin ilişkileriyle ilgili algılarını değerlendirmek için geliştirilmiştir. Ölçek, 5'li Likert tipte ve evet-hayır soruları olmak üzere toplamda 32 maddeden oluşmaktadır. Ölçekten alınan puanlar yüksseldikçe, eşlerin ilişkilerinden aldıkları doyum artmaktadır. Ölçeğin, Türkçe psikometrik özellikleri Fışıloğlu ve Demir (2000) tarafından incelenmiştir. Ölçeğin Türkçe formunun toplam iç tutarlılık katsayısı .92'dir. Alt boyutların iç tutarlılık katsayıları Çift Doyumu, Eşler Arası Bağlılık, Eşler Arası Fikir Birliği ve Duygusal İfade için sırasıyla .83, .82, .84, .61 olarak belirtilmiştir. Yazarlar, ölçeğin toplam puan üzerinden kullanılmasını önermektedir. Bu 
çalışma kapsamında ölçeğin tamamının iç tutarlılık katsayısı .91 olarak bulunmuştur.

Kişilerarası Şemalar Ölçeği (KŞÖ): Ölçek “1982 Kişilerarası Döngü (Kiesler 1983)” modelinden yola çıkarak Hill ve Safran (1994) tarafından geliştirilmiştir. Ölçek, 16 bölümden oluşmakta ve bu bölümler kişilerarası davranışa ilişkin 16 senaryoyu içermektedir. Ölçeğin Türkçe psikometrik özellikleri Boyacıoğlu ve Savaşır (1995) tarafından yapılmıştır. Katılımc1lardan, her bir senaryoyu okuduktan sonra verecekleri tepkiyi hayal etmeleri, kutuplu döngüde tanımlanan davranışlar arasında verecekleri hayali tepkiyi seçmeleri istenmektedir. Ayrıca, verecekleri bu tepki karşısında diğer kişilerin nasıl davranacağına ilişkin beklentilerini ölçüm aracında belirtilen sekiz tepki arasından seçmeleri istenmektedir. Ölçek; anne, baba ve arkadaş olmak üzere üç farklı formdan oluşmaktadır. Bu çalışmada araştırmanın amaçları doğrultusunda Kişilerarası Şemalar Ölçeği- Arkadaş Formu kullanılmıştır. Eşler arasındaki ilişki şemalarının değerlendirilmesi için Arkadaş formundaki, "arkadaşınız" ifadesi "eşiniz" olarak değiștirilmiştir. Ölçekte yer alan kişilerarası tepkilerin iç tutarlılık katsayıları .51 ve .82 aralığında değişmektedir. KŞÖ-Arkadaş formunun alt boyutlarının iç tutarlık katsayısı baskınlık, dostluk, düşmanlık ve pasiflik için sırasıyla $.36, .77, .53$ ve .53 olarak belirtilmiştir (Boyacıŏlu \& Savaşır 1995). Bu çalışma kapsamında baskınlık, dostluk, düşmanlık ve pasiflik alt boyutlarının iç tutarlılık katsayıları sırasıyla $.53, .70, .51$ ve .54 olarak bulunmuştur.

\section{İşlem}

Çalışmaya başlanmadan önce gerekli etik izinler alındıktan sonra, bilgilendirilmiş onam formu, Kişilerarası Şemalar Ölçeği, YIYE II ve Evlilik Uyumu Ölçekleri Hacettepe Üniversitesi'nin farklı birimlerinde çalışan personellerden gönüllü olanlara uygulanmıştır. Veri toplama sürecinde iş yerleri ziyaret edilerek çalışmanın amacı açıklanmış ve ölçüm araçları gönüllü olanlara kapalı zarf içerisinde verilmiştir. Ertesi gün tekrardan bu kişilere ulaşılarak ölçüm araçları toplanmıştır.

\section{Veri Analizi}

Araştırma konuları; bağlanma boyutları, kişilerarası şemalar ya da evlilik uyumu olduğunda cinsiyet fark1 göz önünde bulundurulması gereken bir değişkendir. Bu nedenle, ana araştırma soruları olan aracılık etkileri değerlendirilmeden önce ölçek puanlarında cinsiyetler arası farklar bulunup bulunmadığı Tek Yönlü Varyans analizleri aracılığıyla değerlendirilmiştir.

Bağlanma örüntüleri ve evlilik uyumu arasındaki ilişkide kişilerarası şemaların aracı rolü Preacher ve Hayes (2008) tarafından geliştirilen SPSS makro analizi ile yürütülmüştür (www.afhayes.com). Baron ve Kenny (1986) tarafindan önerilen geleneksel aracı değişken analizinden farklı olarak Preacher ve Hayes (2004) dolaylı etkiyi hesaplamak için önyükleme örneklemi ile alternatif bir yöntem önermektedir. Dolaylı etki, önyükleme örneklemi dağılımı ile orijinal veri setinden çok sayıda örneklemin (örn. 5000) üretilmesi ile değerlendirilmektedir. Dolaylı aracılık etkilerinin istatistiksel olarak anlamlı olması için \%95 güven aralığında sıfır içermemesi gerekmektedir. Bootstrap analizinin, aracı değişkenlerin etkisini değerlendirmek için kullanılan geleneksel yöntemden daha doğru ve güçlü istatistiksel tahminler ürettiği bilinmektedir (Hayes 2009). Ayrıca, aynı anda birden fazla aracı değişkeni test etme imkânı sağlamaktadır.

Figür 1'deki Model A'da X'in (yordayıc1) Y (criterion- değişken) üzerindeki etkisi "toplam etki (c yolu)" olarak adlandırılmaktadır. Model B'de ise X'in Y üzerindeki etkisi M1 ve M2 aracı değiş̧enleri üzerinden yürütülmektedir. $\mathrm{X}$ 'in $\mathrm{Y}$ üzerindeki “direkt etkisi” c' yoludur. $\mathrm{Bu}$ çalışmada bağlanmanın iki boyutu olan kaygı ve kaçınma için iki ayrı dolaylı etki hesaplanmıştır. Buna göre evlilik uyumu yordanan değişken, bağlanmanın kaygı ve kaçınma boyutu yordayıcı değişkenler, kişilerarası şemaların düşmanlık ve dostluk boyutları aracı değişkenler 
olarak incelenmiştir. Dolaylı etkilerin anlamlılığını test etmek için 5000 bootstap önyükleme örneklemine dayanılarak \%95 güven aralığı kullanılmıştır.

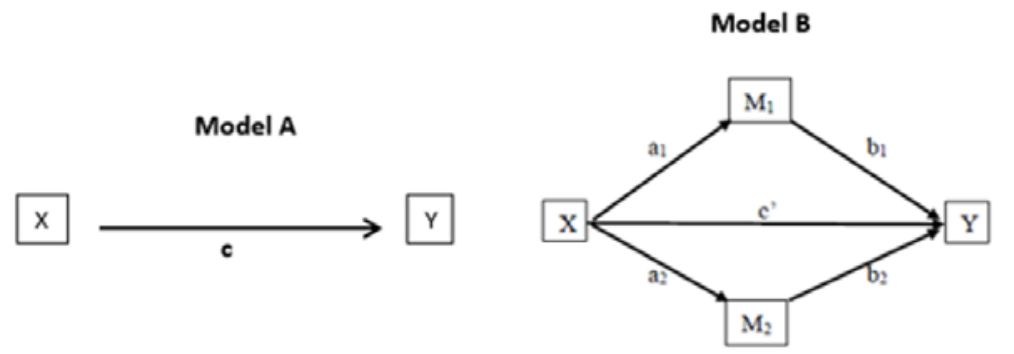

Fig. 1. MODEL A: $X$ 'in $Y$ üzerindeki toplam etkisi; MODEL B: $X$ 'in $Y$ üzerindeki doğrudan etkisi c', $\mathrm{X}^{\prime}$ in $\mathrm{Y}$ üzerindeki dolaylı etkisi $\mathrm{M}_{1}$ ve $\mathrm{M}_{2}$

\section{Bulgular}

Cinsiyet faktörüne göre değişkenler arasındaki farklılıkları incelemek için yapılan analiz bulgularına göre kadınlar ve erkekler arasında evlilik uyumu, kaygılı-kaçınıcı bağlanma puanları açısından anlamlı fark olmadığı gözlenmiştir $(p>.05)$. Bu nedenle, mevcut çalışmada cinsiyet açısında ayrıştırılmadan kadın ve erkekler bir arada değerlendirilmiştir. Ölçek toplam puanları ve alt boyutlarına ilişkin psikometrik özellikler Tablo 1 de sunulmuştur.

Tablo 1. Bağlanma Örüntüleri, Kişilerarası Şemalar ve Evlilik Uyumu Değişkenleri Arasındaki Korelasyon Değerleri $(N=255)$

\begin{tabular}{llllll}
\hline & Ort & SS & Ranj & Max & Min \\
Kaygı & 3.32 & .92 & 4.28 & 5.72 & 1.44 \\
Kaçınıcı & 2.76 & .97 & 4.17 & 5.28 & 1.11 \\
Dostluk & 1.66 & 0.97 & 4.50 & 3. & -1.50 \\
Düşmanııı & 0.25 & 1.39 & 6 & 3 & -3 \\
Pasiflik & 0.19 & 1.2 & 5.50 & 2.50 & -3 \\
Baskınlık & 0.51 & 1.17 & 5 & 2.50 & -2.50 \\
Evlilik Uyumu & 74.92 & 15.41 & 113 & 139 & 26 \\
\hline
\end{tabular}

Değişkenler arasındaki korelasyon katsayıları Tablo 2'de aktarılmıştır. Analiz sonuçlarına göre kaygılı ve kaçınıcı bağlanma örüntüsü ile evlilik uyumu arasında ters yönde orta düzeyde anlamlı ilişki bulunmuştur. Evlilik uyumu, kişilerarası şemalardan dostluk şeması ile pozitif, düşmanlık şeması ile de ters yönde anlamlı ilişki göstermektedir. Baskınlık ve pasiflik kişilerarası şemaları evlilik uyumu ile ilişkili bulunmadığı için analizlerden çıkarılmıştır.

Tablo 2. Değişkenler Arası Korelasyon Analizleri $(N=255)$

\begin{tabular}{|c|c|c|c|c|c|c|}
\hline & \multicolumn{2}{|c|}{ Bağlanma } & \multicolumn{4}{|c|}{ Kișilerarası Șemalar } \\
\hline & Kaygı & Kaçınma & Dost & Düşman & Pasif & Baskın \\
\hline Kaçınma & $.46^{* *}$ & & & & & \\
\hline Dostluk & $-.25^{* *}$ & $-.24^{* *}$ & & & & \\
\hline Düşmanlık & $.25^{* *}$ & $.25^{* *}$ & $-.12^{*}$ & & & \\
\hline Pasiflik & $-.16^{* *}$ & -.12 & .11 & $-.16^{*}$ & & \\
\hline Baskınlık & .02 & -.04 & 0 & -.06 & $-.13^{*}$ & \\
\hline $\begin{array}{l}\text { Evlilik } \\
\text { Uyumu }\end{array}$ & $-.33^{* *}$ & $-.42^{* *}$ & $.33^{* *}$ & $-.44^{* *}$ & .07 & .09 \\
\hline
\end{tabular}

Kaygı: Kaygılı Bağlanma Puanı; Kaçınma: Kaçınıcı Bağlanma Puanı; Düşman: Düşmanlık Kutbu için Tamamlanma Puanı ${ }^{*} p<.01 ;{ }^{* *} p<.001$ 


\section{Bağlanma ve Evlilik Uyumu Arasındaki İlişside Kişilerarası Şemaların Aracı Rolü}

İlk bootstrap analizinde kaygılı bağlanma ile evlilik uyumu arasında dostluk, düşmanlık ve pasiflik kişilerarası şemalarının aracı rolü incelenmiştir. Analiz sonuçlarına göre kaygılı bağlanma; dostluk $(B=-.26, S E=.07, p<.001, \% 95 \mathrm{CI}=[-.40$ ile -.13$]))$ ve düşmanlık $(B=.38$, $S E=.10, p<.001, \% 95 \mathrm{CI}=$ [.18 ile .57]) kişilerarası şemalarını cinsiyet, yaş, eğitim seviyesi, evlilik yaşı, evlilik süresi, çalışma durumu ve çocuk sayısı değişkenleri kontrol edildikten sonra anlamlı olarak yordamaktadır. Pasiflik kişilerarası şeması ile kaygılı bağlanma arasında anlamlı ilişki bulunmamaktadır $(p=.22)$. Bundan sonraki bütün analizlerde bu değişkenlerin etkisi kontrol edilmiştir. Aracı değişkenlerin doğrudan etkisi incelendiğinde ise dostluk $(B=3.32$, $S E=.92, p<.001, \% 95 \mathrm{CI}=[1.50$ ile 5.13] $)$ ve düşmanlık $(B=-3.60, S E=.64, p<.001, \% 95 \mathrm{CI}=[-$ 4.84 ile -2.34]) kişilerarası șemalarının evlilik uyumunu anlamlı olarak yordadığ bulunmuştur. Bununla birlikte, kaygılı bağlanmanın $(B=-4.02, S E=1.02$, \%95 CI= [-6.03 ile -2.01]) evlilik uyumu üzerindeki doğrudan etkisi hâlâ anlamlı olduğu için, kaygılı bağlanma ve evlilik uyumu arasındaki ilişkide dostluk $(B=-.057, S E=.024, \% 95 \mathrm{CI}=[-.112$ ile -.019$])$ ve düşmanlık $(B=-$ $.089, S E=.03, \% 95 \mathrm{CI}=[-.156$ ile -.037$])$ kişilerarası şemaları kısmen aracılık yapmaktadır. Diğer bir ifade ile güven aralığ 1 içerisinde sıfır olmadığ 1 için dostluk ve düşmanlık kişilerarası şeması anlamlı aracı değişkenlerdir. Aracı değişken modeli evlilik uyumunun $\left[R^{2}=.33, F(12\right.$, $228)=9.19, p<.001]$ \%33'lük kısmını açıklamaktadır.

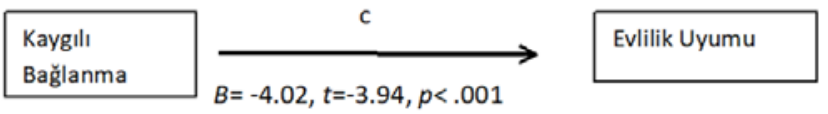

Fig. 2. Model A: Kaygılı bağlanma örüntüsünün evlilik uyumu üzerindeki toplam etkisi

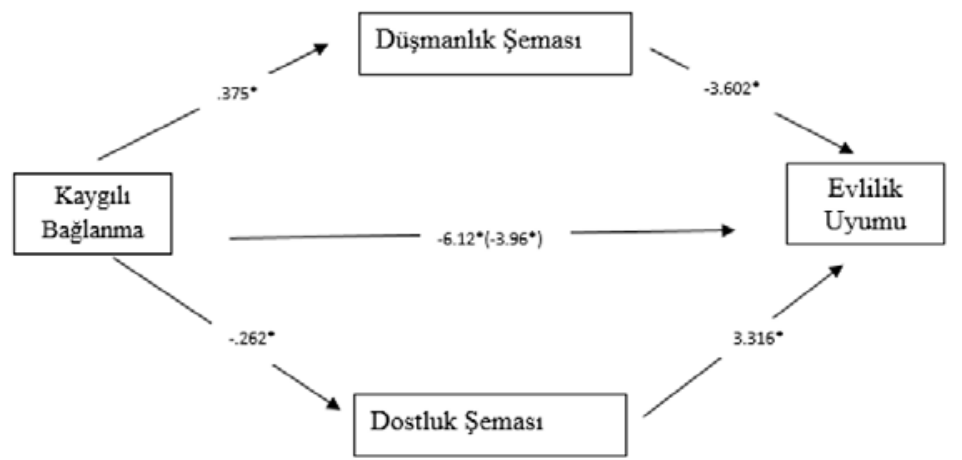

Fig. 3. Model B: Kaygılı bağlanma ve evlilik uyumu arasındaki ilişkide dostluk ve düşmanlık kişilerarası şemalarının aracılık ilişkisi $\left({ }^{*} p<.001\right)$.

$$
\text { Kaçınıcı Bağlanma }
$$$$
B=-6.28, t=-6.42, p<.001
$$

Evlilik Uyumu

Fig 4. Model A: kaçınıcı bağlanmanın evlilik uyumu üzerindeki toplam etkiyi göstermektedir.

İkinci olarak kaçınıcı bağlanma örüntüsünde dostluk ve düşmanlık kişilerarası şemasının aracı rolünün görülmesi için ikinci bir bootstrap analizi yürütülmüştür. Analiz sonuçlarına göre kaçınıcı bağlanma dostluk $(B=-.20, S E=.07, p<.001$, \%95 CI= [-.3347 ile -.066]) ve düşmanlık $(B=.43, S E=.10, p<.001, \% 95 \mathrm{CI}=[.234$ ile .615$])$ kişilerarası şemalarını anlamlı olarak yordamaktadır. Pasiflik kișilerarası șeması ile kaygılı ve kaçınıcı bağlanma örüntüleri arasında anlamlı ilişki bulunmamıştır ( $\mathrm{p}>.05$ ). Aracı değişkenlerin evlilik uyumu üzerindeki direkt etkisi incelendiğinde ise dostluk $(B=3.45, S E=.91, p<.001, \% 95 \mathrm{CI}=[1,705$ ile 5.284]) ve düşmanlık 
$(B=-3.40, S E=.65, p<.001, \% 95 \mathrm{CI}=[-4.377$ ile -2.056$])$ kişilerarası şeması anlamlı olarak yordamaktadır. Ayrıca, kaçınıcı bağlanmanın $(B=-6.28, S E=1.02, \% 95 \mathrm{CI}=[-8.290$ ile -4.267$)$ evlilik uyumu üzerindeki direkt etkisi anlamlı olduğu için, kaçınıcı bağlanma ve evlilik uyumu arasındaki ilişkide dostluk $(B=-.05, S E=.02, \% 95 \mathrm{CI}=[-.0931$ ile -.0131$])$ ve düşmanlık $(B=-$ $.10, S E=.03, \% 95 \mathrm{CI}=$ [-.153 ile -.049]) kişilerarası şemaları kısmen aracılık yapmaktadır. Aracı değişken modeli evlilik uyumunun $\left[R^{2}=.33, F(12,228)=9.45, p<.001\right] \% 33$ 'lük kısmını açıklamaktadır.

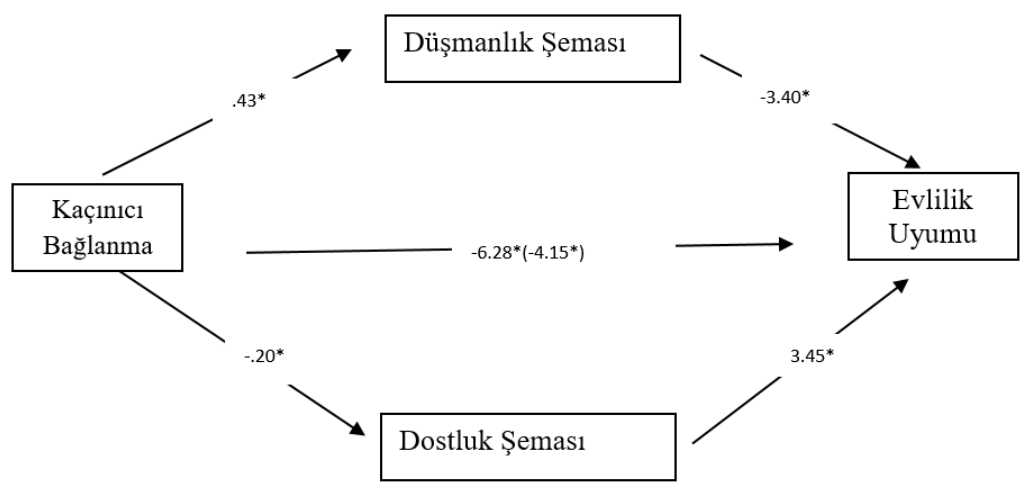

Fig. 5. Model B: Kaçınıcı bağlanma ve evlilik uyumu arasındaki ilişkide dostluk ve düşmanlık kişilerarası şemalarının aracılık ilişkisi $\left({ }^{*} p<.001\right)$

\section{Tartışma}

Doğumdan itibaren anne ile kurduğu ilişki içerisinde, annenin aynalaması ile çocuğun benlik algısı gelişmeye başlar. Anne ile kurulan bu ilk ilişkinin özellikleri sadece çocuğun benlik temsillerinin içeriğini şekillendirmekle kalmaz, diğerlerine ve dünyaya (çevreye) ilişkin beklentilerini de biçimlendirmektedir (Bowlby 1969). Çocuğun büyümesi ile birlikte, anne dişında kurduğu sosyal ilişkilerle birlikte farklı sosyal ağlar oluşsa da erken dönemde anne ile kurulan ilk ilişkide şekillenen benlik temsillerinin tutarlılığını koruduğu düşünülmektedir (Main et al. 1985). Bu bağlamda, yetişkinlik dönemindeki yakın ilişkilerde bu temsiller çiftlerin ilişkilerindeki durumları yorumlanmalarını ve eşlerine verdikleri tepkileri etkileyebileceği düşünülmektedir (Mikulincer \& Shaver 2007). Bu noktadan yola çıkarak Safran ve Segal (1990) çocuklukta oluşturulan bağlanma örüntülerinin daha sonrasında kişilerarası şemaları biçimlendirdiğini belirtmiştir. Bu çalışmada yakın ilişkiler kapsamında anne ile kurulan ikili ilişkiden sonra insan yaşamında önemli bir yerinin olduğu düşünülen evlilik ilişkisi ele alınmıştır. Bu amaçla evlilik uyumu ve bağlanma örüntüleri arasındaki ilişkide kişilerarası şemaların aracı rolü incelenmiştir.

Çalışmanın sonuçları ilk hipotezi desteklemiştir: Evli bireylerin kaygılı ve/veya kaçınıcı bağlanma eğilimleri arttıkça evlilik uyumları azalmaktadır. Bu sonuç alan yazınla oldukça tutarlıdır (Kobak \& Hazan 1991; Mikulincer \& Shaver 2007; Mondor et al. 2011). Ayrica, güvensiz bağlanma örüntüleri kendi içerisinde değerlendirildiğinde kaçınıcı bağlanma puanlarının kaygılı bağlanmaya göre daha kötü evlilik uyumuna işaret ettiği bulunmuştur. Benzer bulgular Türkiye'deki (Tulum 2014) ve yurtdışındaki (örn. Kobak \& Hazan 1991; Mondor et al. 2011) çalışmalarda da desteklenmiştir. Bu farkın kaygılı ve kaçınıcı bağlanma örüntüsüne sahip bireylerin kendilik ve diğerleriyle ilgili algısı ve beklentilerindeki farklılıktan kaynaklanabileceği düşünülmektedir. Kaygılı bağlananlar eşlerinin onaylamama veya dışlama sinyallerine karşı daha duyarlıdırlar. Aynı zamanda sevildiğini, değer verildiğini hissetmek istedikleri için de eşlerinden gelen tepkilere karşı daha tetiktedirler. Bu nedenle, olumsuz tepkiler karşısında kaygıları artsa da, eşleri olumlu bir şekilde yaklaştığında kendileri de olumlu bir tepki verebilirler. Tam tersi, kaçınıcı örüntülerin temel işlevi eşten gelen uyaranlara karşı duyarsızlık oluşturmasıdır. Böylece kişi olumsuz duygulara karşı bir savunma düzeneği geliştirmiş olur. 
Kaçınıcı örüntüleri güçlü olan kişiler hem kendisinin hem de eşinin duygularını fark etmekte ve açılamada zorluk yaşayabilirler. Böylece ilişkide eşlerinden dostça veya düşmanca tepki gelse de tepkisiz kalabilmektedirler. Bu durum, kaçınıcı bağlanan eşin duygu ve düşüncesini ifade edemediği için ilişkide çiftin birbirine karşı yakınlık hissini azaltıp, evlilik doyumlarını düşürebilmektedir (Banse 2004).

Çalışmanın ikinci hipotezi olan kişilerarası şemaların evlilik uyumunu anlamlı olarak yordaması kısmi olarak desteklenmiştir. Analiz sonuçlarına göre, kişilerarası şemalardan dostluk ve düşmanlık boyutları evlilik uyumunu anlamlı olarak yordamaktadır. Pasiflik ve baskınlık boyutları ise evlilik uyumunu anlamlı olarak yordamamaktadır. Bu sonuçlara göre, kişilerarası döngüde yakınlık ekseni evlilik uyumu üzerinde rol oynarken, kontrol ekseninin etkisi bulunmamıștır. Bağlanma sisteminin temel hedefi yakın ilișkilerdeki fiziksel ve duygusal yakınlığın düzenlenmesidir. İlișki içindeki güç dengesinin düzenlenmesi bağlanma sisteminin kuramsal düzeyde açıklama getirdiği konular arasında yer almamaktadır. Bu bulgular ışığında, güvenli bağlanan çiftler eşlerine sevgilerini gösterip yakın davrandıkların da eşlerinden de bu davranışların tamamlanacağını yani yakın, sıcak tepkiler alacaklarına inanmaktadır. Buna karşın kızgınlık, öfke gibi düşmanca davranışlar gösterdiklerinde de tam tersi, eşlerinin anlama, yatıştırma gibi destek içeren davranışlarda bulunacağını beklemektedir. Güvensiz bağlanan çiftlerin kişilerarası davranış örüntüleri incelendiğinde ise bağlanma alan yazını ile tutarlı bulgulara işaret etmektedir. Buna göre evli bireylerin güvensiz bağlanma (kaygı ve kaçınma düzeyleri) örüntüleri arttıkça eşlerine karşı yakın, sıcak davranışlar gösterseler de eşlerinin kendilerine benzer şekilde tepki vermeyeceği beklentisi artmaktadır. Bununla birlikte, güvensiz bağlanma örüntüsüne sahip bireyler, eşlerine karşı kızgınlık, öfke içeren davranışlar sergilediklerinde ise aynı şekilde eşlerinden kızgınlık, öfke gibi bu davranışları tamamlayıcı tepkiler alacaklarına yönelik beklentileri artmaktadır.

Analiz bulguları beraber değerlendirildiğinde güvenli bağlanma örüntüsüne sahip eşler, evlilik ilişkilerinde duygu ve düşüncelerini karşı tarafa rahatça ifade edip, verdikleri tepkiler olumsuz olsa dahi karşı tarafın her zaman olumsuz tepki vermeyeceğini, eşlerinin farklı tepkiler verebileceğini düşünmektedir. Güvenli bağlanan bireylerin, eşlerinden düşmanca tepkiler beklemedikleri için de, kaygı hissetmeyip, ilişki döngüsünü kesmeyerek, eşleri ile yakın ilişkiyi sürdürüp, evliliklerinden daha çok doyum alabildikleri düşünülmektedir (Knapp et al. 2015; Seedall et al. 2015). Bununla ilişkili olarak, duygu ve düşüncelerini karși tarafa daha rahat dile getirebildikleri için de çatışmaları karşılıklı uzlaşı sağlayarak çözebildikleri belirtilmektedir (Tulum 2014; Karagöz-Okutan 2016). Öte yandan, güvensiz bağlanma örüntüsü gösteren bireyler, eşlerine olumsuz bir duygu ifade ettiklerinde eşlerinden de düşmanca bir tepki geleceğini düşündükleri için eşleri ile arasındaki ilişki örüntüsünü evlilikleri için bir tehdit olarak alg1layabilmektedir (Tulum 2014; Karagöz-Okutan 2016). Sonuç olarak, kişilerarası şemalar güvensiz bağlananların neden yakın ilişkilerde zorluk yaşadıklarına yönelik bir açıklama getirmektedir.

Türkiye'de kişilerarası şemaların bağlanma örüntüleri ile ilişkisi farklı örneklemlerde incelenmiştir. Örneğin, Tüzün (2006) çeşitli psikolojik sorunları olan ergenlerin bağlanma örüntüleri ve kişilerarası şemaları arasındaki ilişkiyi incelediği çalışmasında, dostluk ve düşmanlık kişilerarası şemalarında anne ve baba için fark belirtilmezken, arkadaş boyutunda düşmanlık şemasında güvenli ve güvensiz bağlananlar arasında fark bulmuştur. Bir başka çalışmada okul öncesi çocukların bağlanma örüntüleri ve kişilerarası şemaları incelenmiştir. Güvensiz bağlanma örüntüsü gösteren çocukların dostluk, düşmanlık ve pasiflik boyutunda anne ve babalarından daha az tamamlayıcı davranışlar bekledikleri görülmüştür (Uluç, 2005). Annebaba ve çocuk araştırmalarına bakıldığında kontrol ekseninin etkisi bulunmaktadır. Ebeveyn çocuk ilişkisi, ilişkideki hiyerarşik yapı ve anne babanın çocuk üzerindeki hâkimiyeti düşünüldüğünde kontrol ekseninin bu ilişkide anlamlı etkisinin olması beklenebilir. Mevcut çalışmada 
bu bulgulardan farklı olarak kontrol eksenin evlilik uyumu üzerinde etkisi olmamasının, çiftler arasındaki ilişkinin duygusal boyutta gitmesinden kaynaklandığı düşünülmektedir.

Kişilerarası ilişkilerde bağlanma örüntüleri arasındaki bu farkın anlaşılmasının çift ve aile terapilerine önemli katkıları olacaktır. Özellikle, güvensiz bağlanma örüntüsündeki yanlı, olumsuz tutum ve beklentinin terapötik bir hedef olarak çalışılmasının, terapi çıktılarını etkileyebileceği düşünülmektedir. Levy et al. (2018) meta analiz çalışmalarında çiftlerin bağlanma örüntülerinin terapi sonuçları ile ilişkisini incelemiştir. Çalışma bulguları terapi sürecinde çiftlerin güvenli bağlanmalarının arttıkça, terapi çıktılarının da daha olumlu olduğunu göstermektedir. Ayrıca, terapi öncesinde güvenli bağlanma düzeyi düşük kişilerin terapiden daha çok fayda gördükleri belirtilmektedir.

$\mathrm{Bu}$ tartışmalara ek olarak, son dönemdeki çalışmalarda evlilik uyumunun çiftlerin çocuklarının ruh sağlıkları üzerinde de önemli etkisinin olduğu ileri sürülmektedir (Bi et al. 2018; Poulsen et al. 2018). Örneğin, Yazıcı (2016) çalışmasında sağlıksız aile işlevsizliği belirten ergenlerin daha çok davranış problemleri sergilediğini belirtmiştir. Yazar bu durumun eşlerin evlilik uyumunun düştükçe, çocukları ile ilişkilerinde çatışmalarının artmasından, çocuklarına daha az ilgi göstermelerinden ve daha kontrolcü davranışlarda bulunmalarından kaynaklandığını düşünmektedir. Benzer şekilde yoğun evlilik çatışması bildiren babalardan kaygılı bağlananların, çocukları ile kurdukları iletişiminde daha çok olumsuz duygu ifade ettikleri ve daha az olumlu duygu yansıttıkları belirtilmiştir. Bu ilişki örüntüsünde olan çocuklar da babalarına daha az güvenli bağlanmaktadır (Bi et al. 2018).

Ayrıca, bir grup araştırmacı çocuğun aile içerisinde maruz kaldığı ilişki döngülerini ilerleyen dönemde kendi romantik ilişkisine ve çocukları ile kurduğu ilişkiye yansıttığını düşünmektedir. Diğer bir ifade ile anne-bebek arasındaki bağlanma örüntüsünün ve ebeveynlerin evlilik uyumlarının nesiller arası aktarımının olduğu tartışılmaktadır (Jones et al. 2015). Örneğin, Moullin et al. (2018) derleme çalışmasında anne babaların bağlanma örüntüleri ile çocuklarının bağlanma örüntüleri arasında yüksek ilişki bulmuştur. Ayrıca, güvenli bağlanan ebeveynlerin çocuklarının ilerleyen yaşlarda daha iyi eğitim seviyesine sahip olduğu, gelir düzeylerinin daha yüksek olduğu, yakın ilişkilerde daha az çatışma yaşadıkları belirtilmiştir. Dolayısıyla, erken dönemdeki bağlanma deneyimleri hem duygusal hem de bilişsel olarak çocuğa ilerleyen dönemde avantaj sağlamaktadır. Bir başka çalışmada yeni evli çiftlerin bağlanma örüntüleri ile anne babalarının evlilik doyumlarını ve kendi evliliklerinden aldıkları doyumu değerlendirmeleri istenmiştir. Erkeklerde ebeveynlerinin evlilik doyumu direkt olarak kendi evlilik doyumlarını yordarken, kadınlarda bu ilişki bulunamamıştır. Bununla birlikte kadınlarda ebeveynin evlilik doyumu, kadının bağlanma örüntüsü üzerinden dolaylı olarak evlilik doyumu ile ilişkili bulunmuştur (Jarnecke \& South 2013). Diğer bir ifade ile bireyin anne-babasının evlilik ilişkisinin kötü olması erken dönemde ebeveynleri ile kurduğu bağlanma deneyimlerine zarar verebilmektedir. Güvensiz bağlanma geliştiren kişiler de ilerleyen dönemde kendi ilişkilerinde zorluklar yaşıyor olabilirler. Sonuç olarak evlilik uyumu sadece çiftleri değil, çiftin çocuklarını, ailelerin genel işlevsellik düzeyini hatta döngüsel olarak çiftlerin çocuklarının evlilik uyumlarını da etkileyebilmektedir. Bu bağlamda, ilerleyen çalışmalarda evlilik uyumunu düşüren faktörlere yönelik tedavi yaklaşımlarının geliştirilmesi hem çiftlerin hem de çocukların psiko-sosyal gelişimi açısından önemli olacaktır.

Bununla birlikte çalışmanın bazı sınırlılıkları bulunmaktadır. İlk olarak, kişilerarası şemaların değerlendirilmesi için kullanılan KŞÖ’nün kontrol ekseninin alt boyutlarının güvenirlik değerlerinin düşük olması, aracı rollerinin değerlendirilmesinde kısıtlılığa yol açmış olabilir. İkinci olarak, çalışma örnekleminin genel olarak yüksek sosyo-ekonomik düzeyden (SED) oluşmasının, sonuçlarda yanlılık oluşturabileceği düşünülmektedir. İlerleyen çalışmalarda düşük SED'den gelen katılımcılarla çalışma tekrarlanabilir. Son olarak, eşlerin çift olarak kendi 
aralarında karşılaştırılmaması, bireysel farklılıklardan doğabilecek karıştırıcı değişkenlerin kontrol edilmesini mümkün kılmamaktadır. İlerleyen çalışmalarda farklı analiz yöntemleri ile eşlerin kendi aralarında karşılaştırılması daha kapsamlı bilgi elde edilmesini sağlayabilir.

\section{Yazarın Notu}

Çalışma verilerinin bir kısmı 19. Ulusal Psikoloji Kongresi'nde sözel bildiri olarak sunulmuştur.

\section{KAYNAKÇA}

Baldwin M. W. (1992). "Relational Schemas and the Processing of Social Information". Psychological Bulletin 112/3 (1992) 461-484. DOI: 10.1037/0033-2909.112.3.461

Banse R. (2004). "Adult Attachment and Marital Satisfaction: Evidence for Dyadic Configuration Effects". Journal of Social and Personal Relationships 21/2 (2004) 273-282.

Baron R. M. \& Kenny D. A. (1986). "The Moderator-Mediator Variable Distinction in Social Psychological Research: Conceptual, Strategic, and Statistical Considerations”. Journal of Personality and Social Psychology 51/6 (1986) 1173-1182.

Bartholomew K. \& Horowitz L. M. (1991). "Attachment Styles in Young Adults: A Test of a FourCategory Model”. Journal of Personality and Social Psychology 61/2 (1991) 226-224.

Bi S., Haak E. A., Gilbert L. R., El-Sheikh M. \& Keller P. S. (2018). "Father Attachment, Father Emotion Expression, and Children's Attachment to Fathers: The Role of Marital Conflict”.Journal of Family Psychology 32/4 (2018) 456-465. DOI: 10.1037/fam0000395

Boden J. S., Fischer J. L. \& Niehuis S. (2010). "Predicting Marital Adjustment from Young Adults' Initial Levels and Changes in Emotional Intimacy Over Time: A 25-Year Longitudinal Study". Journal of Adult Development 17/3 (2010) 121-134.

Bodenmann G. \& Randall A. K. (2012). "Common Factors in the Enhancement of Dyadic Coping”. Behavior Therapy 43/1 (2012) 88-98.

Bowlby J. (1969). Attachment and Loss: Attachment. New York 1969.

Boyacıoğlu G. \& Savaşır I. (1995). "Kişilerarası Şemalar Ölçeğinin Geçerlik ve Güvenirlik Çalışmasıı". Türk Psikologlar Dergisi 35 (1995) 40-58.

Brennan K. A. Clark C. L. \& Shaver P. R. (1998). "Self- Report Measurement of Adult Attachment: An Integrative Overview”. Eds. J. A. Simpson \& W. S. Rholes, Attachment Theory and Close Relationship (1998) 46-76. New York.

Carr D., Freedman V. A., Cornman J. C. \& Schwarz N. (2014). "Happy Marriage, Happy Life? Marital Quality and Subjective Well-being in Later Life". Journal of Marriage and Family 76 (2014) 930-948.

Collins N. L. \& Feeney B. C. (2004). "Working Models of Attachment Shape Perceptions of Social Support: Evidence from Experimental and Observational Studies". Journal of Personality and Social Psychology 87/3 (2004) 363-383.

Donato S., Parise M., Bertoni A., Finkenauer C. \& Bodenmann G. (2015). "Dyadic Coping Responses and Partners' Perceptions for Couple Satisfaction: An Actor-Partner Interdependence Analysis”. Journal of Social and Personal Relationships 32/5 (2015) 580-600.

Dumlupınar-Aslan M. (2016). Bağlanma Stilleri ve Kişilik Özelliklerinin Evlilik Uyumu Üzerindeki Etkilerinin Araşttrılması. Yüksek Lisans Tezi. Üsküdar Üniversitesi, İstanbul 2016.

Elmas C. (2017). Evli Bireylerin Algıladiklart Sosyal Destek ve Kullandikları Savunma Mekanizmalarinın Evlilik Uyumu ile İlişkisi. Yayımlanmamış Yüksek Lisans Tezi. Beykent Üniversitesi, İstanbul 2017.

Erbek E., Bestepe E., Akar H., Eradamlar N. \& Alpkan R. L. (2005). “Evlilik Uyumu”. Düşünen Adam 18/1 (2005) 39-47.

Erdoğan-Taycan S. \& Çepik-Kuruoğlu A. (2013). "Evlilik Uyumu ile Bağlanma Stilleri ve Mizaç ve Karakter Özellikleri Arasındaki İlişkilerin İncelenmesi”. Türk Psikiyatri Dergisi 24 (2013) 1-10.

Feeney J. A. (2004). "Transfer of Attachment from Parents to Romantic Partners: Effects of Individual and Relationship Variables”. Journal of Family Studies 10 (2004) 220-238.

Fişıloğlu H. \& Demir A. (2000). "Applicability of the Dyadic Adjustment Scale for Measurement of Marital Quality of Turkish Couples”. European Journal of Psychological Assessment 16/3 (2000) 214-218. 
Fraley R. C., Waller N. G. \& Brennan K. A. (2000). "An Item Response Theory Analysis of Self-Report Measures of Adult Attachment”. Journal of Personality and Social Psychology 78 (2000) 350 - 365.

Gallo L. C. \& Smith T. W. (2001). "Attachment Style in Marriage: Adjustment and Responses to Interaction”. Journal of Social and Personal Relationships 18/2 (2001) 263-289.

Gündoğan M. (2015). Eşlerin Bağlanma Tarzları ile Çift Uyum Düzeyi Arasındaki İlişsinin Araştırılması. Yayımlanmamış Uzmanlık Tezi. Osmangazi Üniversitesi, Eskişehir 2005.

Hayes A. F. (2009). "Beyond Baron and Kenny: Statistical Mediation Analysis in the New Millennium”. Communication Monographs 76/4 (2009) 408-420.

Hazan C. D. \& Shaver P. (1987). "Romantic Love Conceptualized as an Attachment Process”. Journal of Personality and Social Psychology 52/3 (1987) 511-524.

Hill C. R. \& Safran J. D. (1994). “Assessing Interpersonal Schemas: Anticipated Responses of Significant Others”. Journal of Social and Clinical Psychology 13 (1994) 366- 379.

Horowitz L. M., Rosenberg S. E. \& Bartholomew K. (1993). "Interpersonal Problems, Attachment Styles, and Outcome in Brief Dynamic Psychotherapy". Journal of Consulting and Clinical Psychology 61/4 (1993) 549-560. DOI: 10.1037/0022-006X.61.4.549

Jarnecke A. M. \& South S. C. (2013). "Attachment Orientations as Mediators in the Intergenerational Transmission of Marital Satisfaction”. Journal of Family Psychology 27/4 (2013) 550-559.

Jones J. D., Cassidy J. \& Shaver P. R. (2015). “Parents' Self-Reported Attachment Styles: A Review of Links with Parenting Behaviors, Emotions, and Cognitions”. Personality and Social Psychology Review 19/1 (2015) 44-76.

Karagöz-Okutan B. (2016). Talep Etme Geri Çekilme Iletişim Örüntüsü ve Evlilik Uyumu: Bağlanma Yaklaşımına Dayalı Bir Çift Modeli. Yayımlanmamış Doktora Tezi. Hacettepe Üniversitesi, Ankara 2016.

Kiesler D. (1983). "The 1982 Interpersonal Circle: A Taxonomy for complementarity in Human Transactions”. Psychological Review 90 (1983) 185-214.

Knapp D. J., Norton A. M. \& Sandberg J. G. (2015). "Family-of-Origin, Relationship Self-Regulation, and Attachment in Marital Relationships”. Contemporary Family Therapy 37/2 (2015) 130-141.

Kobak R. R. \& Hazan C. (1991). "Attachment in Marriage: Effects of Security and Accuracy of Working Models”. Journal of Personality and Social Psychology 60/6 (1991) 861-869.

Levy K. N., Kivity Y., Johnson B. N. \& Gooch C. V. (2018). "Adult Attachment as a Predictor and Moderator of Psychotherapy Outcome: A Meta-Analysis". J. Clin. Psychol. (2018) 1-18. doi.org/10.1002/jclp.22685

MacLean A. P. (2001). Attachment in Marriage: Predicting Marital Satisfaction from Partner Matching Using a Three-Group Typology of Adult Attachment Style. Unpublished Doctoral Dissertation. Purdue University, West Lafayette 2001.

Main M., Kaplan N. \& Cassidy J. (1985). "Security in Infancy, Childhood, and Adulthood: A Move to Level of Representation". Monographs of the Society for Research in Child Development 50 (1985) 66-104.

Markus H. (1977). "Self-Schemata and Information about the Self". Journal of Personality and Social Psychology 35/2 (1977) 63-78.

Mikulincer M. \& Shaver P. (2007). Attachment in Adulthood (Structure, Dynamics and Change). New York 2007.

Minuchin S. (1974). Families and family therapy. Cambridge 1974.

Mondor J., McDuff P., Lussier Y. \& Wright J. (2011). "Couples in Therapy: Actor-Partner Analyses of the Relationships Between Adult Romantic Attachment and Marital Satisfaction". The American Journal of Family Therapy 39/2 (2011) 112-123.

Moullin S., Waldfogel J. \& Washbrook E. (2018). "Parent-child Attachment as a Mechanism of Intergenerational (Dis)Advantage”. Families, Relationships and Societies 7/2 (2018) 265-284. DOI: 10.1332/204674317X15071998786492

Noftle E. E. \& Shaver P. R. (2006). "Attachment Dimensions and the Big Five Personality Traits: Associations and Comparative Ability to Predict Relationship Quality" Journal of Research in Personality 40/2 (2006) 179-208.

Özen A. (2012). Experince and Expression of Emotions in Marital Conflict: An Attachment Theory Perspective. Doctoral Dissertation. METU, Ankara 2012.

Pollard S. E., Riggs S. A. \& Hook J. N. (2014). "Mutual Influences in Adult Romantic Attachment, 
Religious Coping, and Marital Adjustment”. Journal of Family Psychology 28/5 (2014) 5615-624.

Poulsen H. B., Hazen N. \& Jacobvitz D. (2018). "Parents' Prenatal Joint Attachment Representations and Early Caregiving: The Indirect Role of Prenatal Marital Affect”. Attachment \& Human Development 4 (2018) 1-19. DOI: 10.1080/14616734.2018.149 2003

Preacher K. \& J. Hayes A. F. (2004). "SPSS and SAS Procedures for Estimating Indirect Effects in Simple Mediation Models”. Behavior Research Methods, Instruments, \& Computers 36/4 (2004) 717-73.

Preacher K. J. \& Hayes A. F. (2008). "Asymptotic and Resampling Strategies for Assessing and Comparing Indirect Effects in Multiple Mediator Models”. Behavior Research Methods 40/3 (2008) 879-891.

Sabatelliu R. M. (1988). "Measurement Issues in Marital Research: A Review and Critique of Contemporary Survey Instruments”. Journal of Marriage and the Family 50/4 (1988) 891-891.

Safran J. \& Segal Z. (1990). Interpersonal Process in Cognitive Therapy. New York 1990.

Sağlam E. (2016). Evlilik Uyumunu Etkileyen Faktörler: Bağlanma Stilleri ve Aleksitimik Özellikler. Yayımlanmamış Yüksek Lisans Tezi. Fatih Sultan Mehmet Vakıf Üniversitesi, İstanbul 2016.

Seedall R. B., Butler M. H., Zamora J. P. \& Yang C. (2015). “Attachment Change in the Beginning Stages of Therapy: Examining Change Trajectories for Avoidance and Anxiety”. Journal of Marital and Family Therapy 42/2 (2015) 217-230.

Selçuk E., Günaydın G., Sümer N. \& Uysal A. (2005). "Yetişkin Bağlanma Boyutları Için Yeni Bir Ölçüm: Yakın İlişkilerde Yaşantılar Envanteri-II'nin Türk Örnekleminde Psikometrik Açıdan Değerlendirilmesi”. Türk Psikoloji Yazıları 8/16 (2005) 1-11.

Smith T. W. \& Baucom B. R. W. (2017). "Intimate Relationships, Individual Adjustment, and Coronary Heart Disease: Implications of Overlapping Associations in Psychosocial risk". American Psychologist 72/6 (2017) 578-589.

Spanier G. B. (1976). "Measuring Dyadic Adjustment: New Scales for Assessing Quality of Marriage and Similar Dyads". Journal of Marriage and the Family 38 (1976) 15-28.

Sullivan H. S. (1953). The Interpersonal Theory of Psychiatry. New York 1953.

Troxel W. M., DeSantis A., Germain A., Buysse D. J. \& Matthews K. A. (2017). "Marital Conflict and Nocturnal Blood Pressure Dipping in Military Couples”. Health Psychology 36/1 (2017) 31-34.

Tulum S. (2014) Yeni Evli Bireylerde Bağlanma Boyutlarının Evlilik Uyumu Üzerindeki Etkisi: Çatışma Çözüm Stillerinin Aracı Rolü. Yüksek Lisans Tezi. Orta Doğu Teknik Üniversitesi, Ankara 2014.

Tüzün Z. (2006). Çeşitli Psikolojik Sorunları Olan Ergenlerde Bağlanma Biçimleri ve Algılanan Aile Ortamları ile Kişilerarası Şema Örüntüleri Arasındaki Ilişkilerin Objektif ve Projektif Temelli Değerlendirilmesi. Doktora Tezi. Hacettepe Üniversitesi, Ankara 2006.

Uluç S. (2005). Okul Öncesi Çocuklarda Benliğe İlişkin İnançlar, Kişilerarası Şemalar ve Bağlanma İlişkisinin Temsilleri Arasındaki İlişki: Ebeveynlerin Kişilerarası Şemalarının ve Bağlanma Modellerinin Etkisi. Doktora Tezi. Hacettepe Üniversitesi, Ankara 2005.

Whisman M. A., Uebelacker L. A. \& Weinstock L. M. (2004). "Psychopathology and Marital Satisfaction: The Importance of Evaluating Both Partners". Journal of Consulting and Clinical Psychology 72 (2004) 830-838. DOI: 10.1037/0022-006X.72.5.830.

Yalçın H. (2014). "Evlilik Uyumu ile Sosyo-Demografik Özellikler Arasındaki İlişki”. Eğitim ve Öğretim Araştırmaları Dergisi 3/1 (2014) 250-261.

Yazıcı E. N. (2016). Understanding the Impact of Parental Quality, Marital Adjustment and Family Functioning on Behavior Problems of Adolescents. Unpublished Master Thesis. İstanbul Bilgi Üniversitesi, İstanbul 2016.

Young M., Riggs S. \& Kaminski P. (2017). “Family Relations: An Interdisciplinary”. Journal of Applied Family Studies 66/2 (2017) 331-345. 